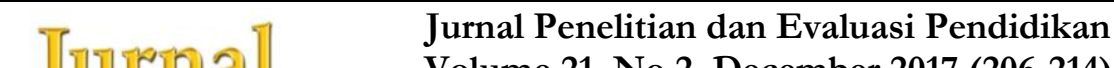

Volume 21, No 2, December 2017 (206-214)

Online: http://journal.uny.ac.id/index.php/jpep

\section{MODEL EVALUASI KINERJA DOSEN: PENGEMBANGAN INSTRUMEN UNTUK MENGEVALUASI KINERJA DOSEN}

\author{
Trie Hartiti Retnowati ${ }^{~ *}$, Djemari Mardapi ${ }^{1}$, Badrun Kartowagiran ${ }^{1}$, Suranto ${ }^{1}$ \\ ${ }^{1}$ Universitas Negeri Yogyakarta \\ 1Jl. Colombo No. 1, Depok, Sleman 55281, Yogyakarta, Indonesia \\ * Corresponding Author. Email: trie_hr@uny.ac.id
}

\begin{abstract}
Abstrak
Tujuan penelitian ini adalah mengembangkan model evaluasi kinerja dosen yang akurat dan terpercaya. Model terdiri atas: instrumen, panduan penskoran, penentuan standar, aplikasi komputer, panduan penilaian, dan panduan pemanfaatan hasil penilaian. Penelitian ini merupakan multy years research selama tiga tahun. Tahun pertama (2017) dilakukan pengembangan instrumen yang akurat dan terpercaya, panduan penskoran, dan penentuan standar. Tahun kedua (2018) dilakukan uji coba penilaian kinerja dosen, produk awal aplikasi komputer, panduan pelaksanaan penilaian, dan panduan pemanfaatan hasil penilaian. Tahun ketiga (2019) dilakukan penilaian kinerja dosen, contoh pemanfaatan hasil penilaian, dan validasi aplikasi komputer. Draf instrumen divalidasi oleh 10 pakar kemudian dihitung validitas isinya dengan formula Aiken $\mathrm{V}$, bukti validitas konstruk menggunakan analisis faktor eksploratori, dan estimasi reliabilitasnya dengan Cronbach Alpha. Hasil penelitian menunjukkan bahwa: (1) semua butir instrumen sudah memenuhi standar validitas isi yakni 0,73 , (2) hasil analisis faktor instrumen kinerja dosen dalam bidang pengajaran menunjukkan bahwa terdapat 3 komponen, yaitu persiapan, pelaksanaan, dan evaluasi dengan indeks reliabilitas Alpha sebesar 0,844, dan (3) berdasarkan kajian teori, FGD, dan bukti empirik, dapat disimpulkan bahwa kinerja dosen dinilai melalui empat aspek yakni kinerja dalam pengajaran, kinerja dalam penelitian, kinerja dalam PPM, dan kapasitas dosen.
\end{abstract}

Kata kunci: instrumen, model evaluasi, kinerja dosen

\section{EVALUATION MODEL OF LECTURER'S PERFORMANCE: DEVELOPING INSTRUMENTS FOR EVALUATING LECTURER'S PERFORMANCE}

\begin{abstract}
The aim of this research is to develop the evaluation model for lercturer performance that is valid and reliable. The model consists of: instruments, scoring manual, act of determining standard, application standard, assessment manual, and utilization manual of the assessment result. This research is a multi-year research. The first year research (2017) focuses on the development of evaluation instruments which is valid and reliable. The second year research (2018) focuses on conducting trial for lerturer performance assessment, initial computer application, the manual of assessment process, and the manual of assessment result utilization. The third year research (2019) focuses on administrating the evaluation for lecturer, the example of assessment result utilization, and validating computer application. The draft of the instrument was validated by 10 experts and analyzed using Aiken $\mathrm{V}$ formula. Besides, exploratory factor analysis was also conducted to prove the construct validity. The reliability was estimated by Alpha Cronbach formula. The result of the research shows that: (1) all instrument items have fullfilled the content validity requirement (0.73), (2) the exploratory factor analysis result of lecturer teaching performance consists of 3 components, including preparation, teaching process, and evaluation with reliability index of 0.844 , and (3) based on the theoretical study, focus group discussion, and empirical evidence, lecturer performance can be assessed by four aspects, including teaching performance, research performance, social service performance, and lecturer capacity.
\end{abstract}

Keywords: instrument, evaluation model, lecturer performance

Permalink/DOI: http:/ / dx.doi.org/10.21831/pep.v21i2.16626 


\section{Pendahuluan}

Perguruan tinggi merupakan salah satu lembaga pendidikan yang ada dalam sistem pendidikan nasional. Perguruan tinggi berkewajiban menyelenggarakan pendidikan, penelitian, dan pengabdian kepada masyarakat seperti tertuang dalam Undangundang Nomor 20 Tahun 2003 tentang Sistem Pendidikan Nasional (Depdiknas, 2003). Tujuan utama pendidikan tinggi adalah untuk memfasilitasi pembelajaran mahasiswa (Nygaard \& Belluigi, 2011, p. 657). Kualitas pendidikan tinggi juga menjadi perhatian lama bagi pengusaha, baik sebagai perekrut lulusan maupun sebagai kolaborator dalam penelitian dan pelatihan (Harvey \& Green, 1993, p. 9). Perguruan tinggi agar dapat mewujudkan kewajibannya dengan baik, tentunya harus didukung oleh komponen-komponen yang terkait. Dalam hal ini komponen tersebut meliputi sarana-prasarana, mahasiswa, dosen, dan staf pendukung. Komponen-komponen tersebut tentunya harus saling dukung mendukung secara sinergis agar kewajiban perguruan tinggi dapat terwujud dengan baik.

Dosen merupakan komponen yang penting dalam menuju perguruan tinggi yang berkualitas. Sebagaimana pendapat Ramli \& Jalinus (2013, p. 72) yang menyatakan bahwa keberadaan pendidik yang bermutu merupakan syarat mutlak hadirnya sistem dan praktik pendidikan yang bermutu. Hal ini selaras dengan tujuan utama perguruan tinggi adalah mencetak sumber daya manusia yang berkualitas di jenjang pendidikan tinggi. Aktivitas utama lembaga ini dalam rangka mencetak sumber daya manusia yang berkualitas baik melalui proses pembelajaran.

Undang-undang Republik Indonesia Nomor 14 Tahun 2005 tentang Guru dan Dosen (Depdiknas, 2005) menyatakan bahwa dosen adalah pendidik profesional dan ilmuwan dengan tugas utama mentransformasikan, mengembangkan, dan menyebarluaskan ilmu pengetahuan, teknologi, dan seni melalui pendidikan, penelitian, dan pengabdian kepada masyarakat. Demikian luas dan kompleksnya tugas seorang dosen maka untuk menjadi dosen, seseorang harus memiliki kemampuan yang tinggi sesuai dengan batasan tersebut. Di sinilah letak pentingnya peran seorang dosen dalam sebuah institusi perguruan tinggi.

Demikian pentingnya peran dosen di dalam aktivitas perguruan tinggi sehingga perlu dijaga kualitas kinerjanya. Kinerja atau performance menurut Armstrong (2000) "... it is a record of a person's accomplishments". Selanjutnya Jones, Jenkin \& Lord (2006, p. 4) mengatakan "performance leads to the conclution that an individual's performance needs to be ganged with both behaviours and outcomes in mind". Dalam arti unjuk kerja, kinerja merupakan kumpulan total dari perilaku yang ditunjukkan seseorang pekerja, dengan demikian kinerja dosen adalah hasil yang dicapai oleh dosen dalam melaksanakan tugas yang dibebankan kepadanya dan menjadi tanggung jawab dosen didasarkan kepada kecakapan, pengalaman, dan kesungguhan dalam rentang waktu tertentu.

Apabila dikaitkan dengan tugas utamanya sebagai penyelenggara pembelajaran, ada hubungan antara kinerja dosen dengan kualitas pembelajaran yang diselenggarakan. Hal ini sejalan dengan hasil penelitian Sharko, Sharko, Demi, \& Baholli (2015, p. 93) yang menemukan bahwa pengetahuan pendidik, keterbaruan bahan ajar, dan pengelolaan kelas berpengaruh terhadap prestasi belajar peserta didik. Long, Ibrahim \& Kowang (2014, p. 37) menyatakan bahwa pengetahuan tentang mata kuliah, kejelasan presentasi, interaksi dengan siswa, kreativitas mengajar, mengklarifikasi hasil belajar, dan aktivitas kelas secara signifikan berhubungan dengan kepuasan mahasiswa. Selanjutnya Muzenda (2013, p. 6) juga menyatakan bahwa pengetahuan tentang mata kuliah yang diampu, keterampilan mengajar, kehadiran dosen, dan sikap dosen berpengaruh signifikan terhadap prestasi akademik mahasiswa. Selain itu, Kamsinah (2008, p. 102) menyatakan bahwa pendidik merupakan salah satu faktor penting untuk mengarahkan peserta didik agar lebih memahami materi dengan berbagai cara yang telah diputuskan dalam situasi dan kondisi tertentu 
secara sistematis untuk mencapai tujuan pembelajaran.

Marzano, Frontier, \& Livingston (2011) mengatakan bahwa semakin banyak kegiatan positif pendidik di dalam kelas, semakin tinggi prestasi belajar peserta didik. Ahli lain, Barber \& Mourshed (2012) mengatakan bahwa prestasi belajar peserta didik dimulai dari pendidik dan kepala sekolah yang efektif. Bahkan di bagian lain Barber \& Mourshed (2012) menjelaskan bahwa "student placed with high performing teachers will progress three times as fast as those placed with low performing teachers".

Menurut Undang-undang Republik Indonesia Nomor 14 Tahun 2005 tentang Guru dan Dosen pada Pasal 60 (Depdiknas, 2005) dijelaskan bahwa dalam melaksanakan tugas keprofesionalannya dosen berkewajiban melaksanakan pendidikan, penelitian, dan pengabdian pada masyarakat. Tiga unsur tersebut merupakan tri dharma perguruan tinggi. Hal ini mengindikasikan bahwa selain dalam bidang pengajaran, dosen juga wajib melaksanakan penelitian dan pengabdian pada masyarakat (PPM). Dosen merupakan pendidik yang profesional sehingga harus mampu memecahkan permasalahan dengan melaksanakan penelitian dan PPM. Oleh karena itu kinerja dosen dalam bidang penelitian dan PPM perlu untuk dievaluasi.

Undang-Undang tentang Guru dan Dosen tersebut juga menjelaskan bahwa dosen memiliki kewajiban untuk meningkatkan dan mengembangkan kualifikasi akademik dan kompetensi secara berkelanjutan sejalan dengan perkembangan ilmu pengetahuan, teknologi, dan seni. Tidak hanya melaksanakan tri dharma perguruan tinggi saja, namun dosen dituntut untuk meningkatkan kapasitasnya dalam kualifikasi akademik dan kompetensi yang sesuai dengan bidang keahliannya.

Beberapa hasil penelitian dan peraturan perundang-undangan yang telah dipaparkan di atas menunjukkan bahwa kinerja dosen merupakan faktor utama dalam menjaga kualitas pendidikan. Bila kinerja dosen dapat terjaga dengan baik maka hasil proses pendidikan yang diperoleh tetap berkualitas de- ngan baik. Dalam rangka mewujudkan kondisi ini diperlukan suatu penilaian yang kontinu terhadap kinerja dosen agar diperoleh informasi yang terkini mengenai kondisi kinerja dosen. Dengan harapan apabila terjadi penurunan kinerja dosen akan segera diketahui dan dapat diberikan tindakan yang tepat.

$\mathrm{Hal}$ ini sejalan dengan hasil penelitian Peleyeju \& Ojebiyi (2013) yang merekomendasikan bahwa pengelola perguruan tinggi harus menjamin penilaian kinerja dosen secara menyeluruh dan terus menerus dalam rangka meningkatkan kualitas dosen dan kualitas manajemen secara keseluruhan di perguruan tinggi. Lebih ditekankan lagi oleh Bai, Rajput, Hussain, \& Khoja (2014, p. 117) menyatakan bahwa evaluasi kinerja dosen merupakan tantangan serius bagi pengelol perguruan tinggi. Selanjutnya, Langen (2011, p. 185) menyatakan bahwa evaluasi kinerja dosen bertujuan untuk mengembangkan pemahaman yang lebih baik tentang praktik evaluasi sehingga pengelola pendidikan tinggi dapat memastikan bahwa proses pembelajaran dapat terlaksana dengan baik.

Menurut Berk (1986) penilaian kinerja adalah proses mengumpulkan data dengan cara pengamatan yang sistematik untuk membuat keputusan tentang individu. Ada lima aspek utama yang tersirat dan tersurat pada definisi tersebut, yaitu proses, pengumpulan data, pengamatan sistematik, integrasi data, dan keputusan individu. Selanjutnya Cronbach (1985) menjelaskan bahwa semua tes pada dasarnya adalah untuk mengukur kinerja dalam suatu segi. Penilaian kinerja biasanya digunakan terhadap suatu tugas yang membutuhkan respons nonverbal, misal tes praktek untuk mengajar, melukis, menyanyi, dan melawak.. Tes kinerja mengacu pada suatu standar yang ingin dicapai atau yang ditetapkan sebagai batas minimum yang harus bisa dilakukan peserta tes, sehingga standar yang ingin dicapai harus ditetapkan lebih dahulu.

Pada penilaian kinerja, seseorang dapat disuruh untuk melakukan respon ganda terhadap suatu pertanyaan sesuai dengan suatu ketetapan tertentu (Yen, 1993). Respons 
ganda ini merupakan informasi yang dibutuhkan untuk menentukan kinerja seseorang dalam bidang tertentu. Oleh karena itu pada penilaian kinerja, dimensi yang diukur tidak hanya satu dimensi.

Penilaian kinerja dosen erat kaitannya dengan pemberian reward and punishment, namun memang tidak mudah dalam pelaksanakannya. Sebagaimana hasil penelitian Basuki (2004, p.104) yang menyatakan bahwa tidak mudah mengintegrasikan antara penilaian kinerja dosen dengan reward and punishment system. Selanjutnya Dengan demikian perlu adanya sistem penilaian kinerja dosen yang komprehensif.

Kegiatan yang harus dilakukan adalah evaluasi kinerja dosen bukan hanya sekedar penilaian kinerja dosen. Hal ini perlu ditegaskan agar hasil penilaian kinerja dosen tidak hanya digunakan untuk mendeskripsikan kinerja masing-masing dosen tetapi juga digunakan untuk pembinaan kinerja dosen secara menyeluruh dan berkesinambungan. $\mathrm{Hal}$ ini selaras dengan Rencana Induk Penelitian (RIP) Universitas Negeri Yogyakarta (UNY) Tahun 2016-2020 dalam Isu Strategis Bidang Kependidikan Nomor 5 tentang Penguatan Kelembagaan Pendidikan (Universitas Negeri Yogyakarta, 2016, p. 51). Dalam RIP UNY dijelaskan bahwa salah satu tema penelitian tentang penguatan kelembagaan pendidikan yakni penelitian pendidikan untuk menilai kinerja pendidik dan tenaga kependidikan.

Permasalahan yang muncul dari latar belakang masalah ini adalah evaluasi kinerja dosen yang bagaimanakah yang mampu memberikan informasi yang akurat dan terpercaya sehingga informasi tersebut dapat digunakan untuk melakukan pembinaan kinerja dosen secara menyeluruh dan berkesinambungan. Tujuan penelitian ini adalah mengembangkan suatu model evaluasi kinerja dosen yang mampu memberikan informasi yang akurat dan terpercaya. Informasi hasil penilaian kinerja dosen ini selanjutnya digunakan sebagai bahan pertimbangan utama dalam melakukan pembinaan kinerja dosen secara menyeluruh dan berkesinambungan. Hasil penelitian ini dapat dimanfaatkan oleh pimpinan fakultas untuk mengetahui peta kinerja dosen dan kemudian melaksanaan pembinaan sesuai dengan hasil evaluasi.

\section{Metode Penelitian}

Penelitian ini termasuk design and development research. Model evaluasi kinerja dosen dalam penelitian ini terdiri atas: instrumen, panduan penskoran, penentuan standar, aplikasi komputer untuk menganalisis sekaligus menampilkan hasil penilaian, panduan untuk melakukan penilaian, dan panduan untuk memanfaatkan hasil penilaian.

Penelitian ini merupakan multy years research yang dilaksanakan selama tiga tahun. Tahun pertama (2017) dilakukan pengembangan instrumen yang akurat dan terpercaya, panduan penskoran, dan penentuan kriteria pemenuhan standar. Untuk mendapatkan instrumen yang akurat dan terpercaya maka draf instrumen juga akan diujicobakan sehingga dapat dibuktikan validitas dan estimasi reliabilitasnya. Tahun kedua (2018) dilakukan uji coba penilaian kinerja dosen, produk awal aplikasi komputer, panduan pelaksanaan penilaian kinerja dosen, dan panduan pelaksanaan pemanfaatan hasil penilaian. Tahun ketiga (2019) dilakukan penilaian kinerja dosen, contoh pemanfaatan hasil penilaian kinerja dosen, dan validasi aplikasi komputer.

Tahun pertama (2017) kegiatan yang dilakukan dalam rangka pengembangan instrumen kinerja dosen yaitu: (1) penyusunan konstruk kinerja dosen, (2) penyusunan kisikisi instrumen kinerja dosen, (3) reviu kisikisi instrumen yang sudah dibuat, (4) penyempurnaan kisi-kisi instrumen kinerja dosen, (5) penyusunan butir-butir instrumen kinerja dosen, (6) reviu butir-butir instrumen kinerja dosen, (7) penyempurnaan butir-butir instrumen kinerja dosen, (8) pelaksanaan validasi instrumen kinerja dosen, dan (8) analisis validitas isi instrumen kinerja dosen, (9) uji coba instrumen, dan (10) pembuktian validitas konstruk instrumen kinerja dosen.

Instrumen yang dikembangkan pada tahun pertama (2017) adalah instrumen 
yang digunakan untuk mengungkap kinerja dosen dalam menyelesaikan tugasnya, antara lain: (1) melaksanakan pengajaran, (2) melaksanakan penelitian, (3) melakukan pengabdian kepada masyarakat (PPM), dan (4) kapasitas dosen.

Instrumen kinerja dosen dalam melaksanakan pengajaran berupa angket yang diisi oleh mahasiswa. Instrumen kinerja dosen dalam melaksanakan penelitian dan PPM berupa lembar penilaian yang diisi oleh dosen yang bersangkutan, Bagian Akademik Fakultas, dan Bagian Data dan Informasi Lembaga Penelitian dan Pengabdian pada Masyarakat (LPPM) UNY. Selanjutnya Instrumen kinerja dosen yang berkaitan dengan kapasitas dosen berupa lembar isian yang diisi oleh dosen yang bersangkutan.

Instrumen penilaian kinerja dosen yang dikembangkan dalam penelitian ini diuji coba untuk mengetahuai validitas dan reliabilitas instrumen yang dikembangkan. Uji coba digunakan untuk menentukan draf konstruk instrumen penilaian kinerja dosen dengan menggunakan analisis faktor eksploratori. Responden penelitian yang digunakan dalam uji coba instrumen adalah 21 dosen dan 200 mahasiswa Universitas Negeri Yogyakarta (UNY) yang diambil secara acak.

Data hasil uji coba ini selanjutnya dianalisis dengan analisis faktor eksploratori. Dalam rangka sinkronisasi data tentang penelitian dan PPM yang sudah diisi oleh dosen, ditambahakan juga responden Bagian Akademik Fakultas dan Bagian Data Informasi LPPM UNY untuk mensinkronkan data penelitian. Draf instrumen divalidasi oleh 10 pakar kemudian dihitung validitas isinya dengan formula Aiken V. Data yang terkumpul melalui uji coba kemudian dianalisis dengan menggunakan analisis faktor eksploratori untuk menguji validitas konstruk. Estimasi reliabilitas instrumen dilakukan dengan dengan formula Cronbach Alpha.

\section{Hasil Penelitian dan Pembahasan}

Hasil

Target hasil penelitian tahun pertama ini yakni dilakukan pengembangan instru- men kinerja dosen yang akurat dan terpercaya, panduan penskoran, dan penentuan kriteria pemenuhan standar. Proses penyusunan instrumen penilaian kinerja dosen dilakukan meliputi beberapa tahap, yaitu: (1) penyusunan konstruk kinerja dosen, (2) penyusunan kisi-kisi instrumen kinerja dosen, (3) reviu kisi-kisi instrumen yang sudah dibuat, (4) penyempurnaan kisi-kisi instrumen kinerja dosen, (5) penyusunan butir-butir instrumen kinerja dosen, (6) review butir-butir instrumen kinerja dosen, (7) penyempurnaan butir-butir instrumen kinerja dosen, (8) pelaksanaan validasi instrumen kinerja dosen, dan (8) analisis validitas isi instrumen kinerja dosen, (9) uji coba instrumen, dan (10) pembuktian validitas konstruk instrumen kinerja dosen.

Penyusunan konstruk kinerja dosen dilakukan melalui kajian teori dan kajian penelitian yang relevan. Hasil dari kajian pustaka menunjukkan bahwa konstruk kinerja dosen meliputi tiga aspek yakni (1) kinerja dalam pengajaran, (2) kinerja dalam penelitian, dan (3) kinerja dalam PPM. Selanjutnya berdasarkan konstruk tersebut disusun kisi-kisi instrumen penilaian kinerja dosen. Kisi-kisi instrumen yang sudah dibuat kemudian direviu dan disempurnakan oleh tim peneliti. Kemudian dilakukan penyusunan butir-butir instrumen kinerja dosen. Instrumen yang sudah tersusun divalidasi dengan teknik expert judgment.

Validasi instrumen penilaian kinerja dosen dilakukan oleh 10 orang pakar (expert) dengan kegiatan Focus Group Discussion (FGD). Para validator memberikan skor ketepatan butir instrumen dengan indikator yang sudah dibuat. Skor penilaian tertinggi yakni 4 dan terendah sama dengan 1 . Hasil penilaian dari para pakar tersebut diolah menggunakan rumus Aiken $\mathrm{V}$ untuk memperoleh skor validitas isinya.

Hasil analisis validitas isi instrumen model evaluasi kinerja dosen dengan Aiken $\mathrm{V}$ menunjukkan bahwa semua butir instrumen sudah memenuhi standar validitas isi yakni 0,73 . Hasil FGD juga memberikan masukan terkait aspek kinerja dosen yang belum masuk ke dalam tiga aspek yang su- 
dah dijelaskan di atas. Tambahan aspek tersebut yakni aspek kapasitas dosen, sehingga kinerja dosen terdiri atas kinerja dalam pengajaran, penelitian, PPM, dan kapasitas dosen.

Hasil pengembangan instrumen penilaian kinerja dosen seperti yang disajikan dalam Gambar 1 menunjukkan bahwa kinerja dosen dinilai melalui empat aspek yakni (1) kinerja dalam pengajaran, (2) kinerja dalam penelitian, (3) kinerja dalam PPM, dan (4) kapasitas dosen dimana instrumen penilaian kinerja dosen tersebut terdiri atas 53 butir.

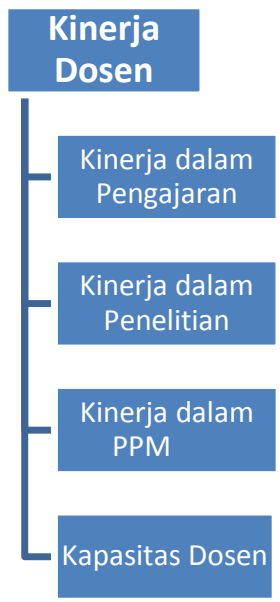

Gambar 1. Aspek Penilaian Kinerja

Dosen

Instrumen kinerja dosen dalam bidang pengajaran berupa angket yang diisi oleh mahasiswa. Angket tersebut terdiri atas 22 butir pernyataan, dimana 20 butir dengan skala Likert yang dimodifikasi dan 2 butir dengan skala Guttman. Instrumen kinerja dosen dalam bidang penelitian, PPM, dan kapasitas dosen berupa angket semi tertutup yang diisi oleh dosen. Selanjutnya hasil isian dosen ini dikroscek dengan lembar isian tentang penelitian dan PPM dosen yang diisi oleh Bagian Akademik Fakultas dan Bagian Data Infromasi LPPM UNY.

Tabel 1. KMO and Bartlett's Test

Kaiser-Meyer-Olkin Measure of $\quad .836$ Sampling Adequacy.

\begin{tabular}{lcr}
\hline Bartlett's Test & Approx. Chi-Square & 1229.158 \\
of Sphericity & Df & 190 \\
& Sig. & .000 \\
\hline
\end{tabular}

Tabel 1 menunjukkan hasil analisis validitas konstruk instrumen kinerja dosen dalam bidang pengajaran dengan menggunakan analisis faktor eksploratori diperoleh nilai $\mathrm{KMO}$ sebesar 0,836. Karena nilai $\mathrm{KMO}=0,836>0,5$ maka analisis faktor dapat dilanjutkan.

Tabel 2. Rotated Component Matrix ${ }^{a}$

\begin{tabular}{lccc}
\hline & \multicolumn{3}{c}{ Component } \\
\cline { 2 - 4 } & 1 & 2 & 3 \\
\hline SMEAN(item09) & .766 & & \\
SMEAN(item08) & .754 & & \\
SMEAN(item13) & .622 & & \\
SMEAN(item11) & .577 & & \\
SMEAN(item12) & .560 & & \\
SMEAN(item17) & .554 & & \\
SMEAN(item07) & .537 & & \\
SMEAN(item20) & .418 & .349 & \\
SMEAN(item19) & & .334 & \\
SMEAN(item10) & & .785 & \\
SMEAN(item16) & & .780 & \\
SMEAN(item18) & & .731 & \\
SMEAN(item14) & & .466 & \\
SMEAN(item15) & & & .687 \\
SMEAN(item03) & & & .652 \\
SMEAN(item04) & & & .606 \\
SMEAN(item02) & & & .303 \\
SMEAN(item06) & & & .451 \\
SMEAN(item05) & & & .397 \\
SMEAN(item01) & & & \\
\end{tabular}

Hasil analisis faktor menunjukkan bahwa terdapat 3 komponen kinerja dosen dalam bidang pengajaran yaitu persiapan, pelaksanaan, dan evaluasi sebagaimana disajikan pada Tabel 2. Komponen persiapan terdiri atas 6 butir, komponen pelaksanaan terdiri atas 8 butir, dan komponen penilaian terdiri atas 6 butir. Hasil analisis faktor eksploratori ini sesuai dengan kajian teori yang telah dilakukan. Selanjutnya estimasi reliabilitas instrumen kinerja dosen dalam bidang pengajaran yang dilakukan dengan formula Cronbach Alpha diperoleh skor 0,844 sebagaimana disajikan dalam Tabel 3 .

Tabel 3. Reliability Statistics

\begin{tabular}{cc}
\hline Cronbach's Alpha & N of Items \\
\hline .844 & 20 \\
\hline
\end{tabular}


Pembahasan

Hasil pengembangan instrumen penilaian kinerja dosen memperoleh hasil bahwa kinerja dosen dinilai melalui empat aspek yakni (1) kinerja dalam pengajaran, (2) kinerja dalam penelitian, (3) kinerja dalam PPM, dan (4) kapasitas dosen. Hasil ini sesuai dengan Undang-undang Republik Indonesia Nomor 14 Tahun 2005 tentang Guru dan Dosen (Depdiknas, 2005) yang menyebutkan bahwa tugas utama seorang dosen yakni melaksanakan pendidikan, penelitian, dan pengabdian kepada masyarakat.

Analisis validitas isi instrumen model evaluasi kinerja dosen dengan Aiken $\mathrm{V}$ menunjukkan bahwa semua butir instrumen sudah memenuhi standar validitas isi yakni 0,73 (Aiken, 1985, p. 134). Estimasi reliabilitas instrumen kinerja dosen dalam bidang pengajaran yang dilakukan dengan Cronbach Alpha diperoleh skor 0,844. Hal ini menunjukkan bahwa reliabilitas instrumen sangat tinggi. Dengan demikian dapat dipastikan bahwa instrumen tersebut dapat dipertanggung jawabkan keandalannya.

Analisis faktor eksploratori menunjukkan bahwa terdapat 3 komponen kinerja dosen dalam bidang pengajaran yaitu persiapan, pelaksanaan, dan evaluasi. Hal ini relevan dengan Pasal 60 Undang-undang Republik Indonesia Nomor 14 Tahun 2005 tentang Guru dan Dosen (Depdiknas, 2005) yang menjelaskan bahwa dalam melaksanakan tugas keprofesionalannya dosen berkewajiban merencanakan, melaksanakan proses pembelajaran, serta menilai dan mengevaluasi hasil pembelajaran. Hasil analisis faktor tersebut juga selaras dengan pendapat Shafa (2014, p. 99) yang menyatakan bahwa proses pembelajaran berfokus pada bagaimana guru merencanakan, menerapkan, dan mengevaluasi proses pembelajaran.

Kinerja dosen dalam bidang pengajaran tentu saja membutuhkan kemampuan akademik yang bagus. Selaras dengan hasil penelitian Sukirno \& Siengthai (2011, p. 494) yang menyatakan bahwa prestasi akademik dosen memiliki pengaruh yang signifikan terhadap kinerja dosen. Lebih lanjut lagi, Amin \& Khan (2009, p. 9) menyatakan bahwa kemampuan pribadi dan proses belajar mengajar merupakan faktor paling penting untuk mengevaluasi kinerja dosen dibandingkan dengan keterampilan administratif, faktor tanggung jawab dan ketepatan waktu, faktor kompensasi dan penghargaan, serta faktor keamanan kerja dan ingkungan.

Kinerja dosen dalam penelitian, PPM, dan kapasitas dosen juga penting untuk dievaluasi. Selaras dengan hasil penelitian Bai, et al (2015, p. 117) yang menyatakan bahwa perguruan tinggi perlu mengevaluasi kinerja dosen dalam perolehan hibah penelitian, profil penelitian, evaluasi siswa, publikasi, dan tanggung jawab akademik. Hasil penelitian Pramudyo (2010, p. 1) juga menemukan bahwa kompetensi dosen berpengaruh terhadap kinerja dosen. Kompetensi dosen di sini yang dimaksud yakni kompetensi dalam bidang pengajaran, penelitian, dan PPM.

Hasil uji coba terbatas menunjukkan bahwa kinerja dosen dalam pembelajaran masih terdapat kekurangan yaitu pada aspek pe-nilaian. Pada aspek perencanaan pembelajaran, kinerja dosen masuk dalam kategori sangat baik dan baik. Aspek pelaksanaan pembelajaran sebagian besar termasuk dalam kategori baik, namun ada yang kurang baik. Sementara itu pada aspek penilaian sebagian besar masuk ke dalam kategori kurang baik. Hal ini dikarenakan dosen sudah baik dalam merencanakan dan melaksanakan pembelajaran, namun masih belum baik dalam melaksanakan penilaian. Kinerja dosen dalam melaksanakan penilaian perlu menjadi perhatian utama. Selaras dengan hasil penelitian Ruslan (2010, p. 230) yang menunjukkan bahwa kepuasan mahasiswa terhadap penilaian yang dilakukan dosen memiliki hubungan yang signifikan dengan kinerja dosen.

Kapasitas dosen dalam kaitannya dengan pengalaman mengajar, menguji, membimbing, menjadi dosen tamu di perguruan tinggi lain serta publikasi artikel ilmiah baik pada jurnal nasional maupun internasional terindeks masih kurang. Selanjutnya kinerja dosen dalam bidang penelitian dan PPM juga masih kurang. Hal ini dikarenakan be- 
berapa dosen yang menjadi sampel penelitian masih dalam status tugas belajar untuk menyelesaikan studi doktoralnya. Selian itu, disebabkan juga instrumen penelitian ini memperhatikan skala atau level kegiatan yang diberi bobot berbeda, misalnya untuk skala lokal, nasional, dan internasional.

\section{Simpulan}

Berdasarkan hasil penelitian dan pembahasan, maka dapat disimpulkan beberapa hal yaitu: (1) hasil pengembangan instrumen penilaian kinerja dosen sesuai dengan kajian teori, FGD, dan bukti empirik diperoleh hasil bahwa kinerja dosen dinilai melalui empat aspek yakni (a) kinerja dalam pengajaran, (b) kinerja dalam penelitian, (c) kinerja dalam PPM, dan (d) kapasitas dosen; (2) hasil analisis validitas isi menunjukkan bahwa semua butir instrumen sudah memenuhi standar validitas isi yakni 0,73 ; dan (3) hasil analisis faktor menunjukkan bahwa terdapat 3 komponen kinerja dosen dalam bidang pengajaran yaitu persiapan, pelaksanaan, dan evaluasi dengan indeks reliabilitas Alpha sebesar 0,844.

Sesuai dengan simpulan tersebut maka dapat dirumuskan beberapa saran yaitu: (1) sebaiknya instrumen penilaian kinerja dosen, pedoman penskoran, dan standar capaian kinerja dosen dapat menjadi acuan penilaian kinerja dosen, dan (2) diharapkan kerjasama yang baik dan proaktif dari bapak ibu dosen yang terlibat sebagai sampel penelitian.

\section{Ucapan Terima Kasih}

Penelitian ini didanai oleh Direktorat Riset dan Pengabdian kepada Masyarakat (DRPM) Kementerian Riset, Teknologi, dan Pendidikan Tinggi tahun anggaran 2017. Peneliti berterima kasih kepada Pimpinan Fakultas di Lingkungan Universitas Negeri Yogyakarta (UNY) dan Pimpinan Lembaga Penelitian dan Pengabdian pada Masyarakat (LPPM) UNY yang telah memberikan izin untuk penelitian ini. Peneliti juga menyampaikan terima kasih kepada berbagai pihak yang telah membantu terselenggarakannya penelitian ini.

\section{Daftar Pustaka}

Aiken, L. R. (1985). Three coefficients for analyzing the reliability and validity of ratings. Educational and Psychological Measurement, 45(1), 131-142. https://doi.org/10.1177/00131644854 51012

Amin, H. U., \& Khan, A. R. (2009). Acquiring knowledge for evaluation of teachers performance in higher education using a questionnaire. Journal of Computer Science and Information Security, 2(1), 7. Retrieved from http://arxiv.org/abs/0906.4663

Armstrong, M. (2000). Performance management. London: Kogan Page.

Bai, S., Rajput, Q., Hussain, S., \& Khoja, S. A. (2014). Faculty performance evaluation system: An ontological approach. Proceedings of IEEE/ACS International Conference on Computer Systems and Applications, AICCSA (Vol. 2014, pp. 117-124). IEEE Computer Society. https://doi.org/ 10.1109/AICCSA.2014.7073187.

Barber, M \& Mourshed, M. (2012). Profesional development international. New York: Pearson.

Basuki, A. (2004). Implementasi sistem jaminan mutu (quality assurance) proses pembelajaran di perguruan tingggi. Jurnal Penelitian dan Evaluasi Pendidikan, 1(6), 104-113. https://doi.org/10.21831/PEP.V6I1.2 042

Berk, A. (1986). Performance assessment. Baltimore: The Johns Hopkins University Press.

Cronbach, L. J. (1985). Essential of psychological testing. New York: Harper and Ross.

Depdiknas. Undang-Undang Nomor 20 Tahun 2003 tentang Sistem Pendidikan Nasional (2003). Jakarta.

Depdiknas. Undang-Undang No. 14 Tahun 2005 tentang Guru dan Dosen (2005). Jakarta.

Harvey, L. \& Green, D. (1993). Defining 
quality. Assessment \& Evaluation in

Higher Education, 18(1), 9-34.

Jones, J., Jenkin, M., \& Lord, S. (2006). Developing effective teacher performance. California: SAGE Publishing Company.

Kamsinah. (2008). Metode dalam proses pembelajaran: studi tentang ragam dan implementasinya. Lentera Pendidikan, 11(1), 102. Retrieved from https://www.academia.edu/6806623. /metode_dalam_proses_pembelajaran _kamsinah_101_metode_dalam_prose s_pembelajaran_Studi_tentang_Ragam _dan_Implementasinya_Oleh_Kamsin ah.

Langen, J. M. (2011). Evaluation of adjunct faculty in higher education institutions. Assessment and Evaluation in Higher Education, 36(2), 185-196. https://doi.org/10.1080/02602930903 221501.

Long, C. S., Ibrahim, Z., \& Kowang, T. O. (2014). An analysis on the relationship between lecturers competencies and students satisfaction. International Education Studies, 7(1), 37-46. https://doi.org/10.5539/ies.v7n1p3.

Marzano, R.J. Frontier, T., \& Livingston, D. (2011). Effective supervision. Alexandria: ASCD.

Muzenda, A. (2013). Lecturers' competences and students' academic performance. International Journal of Humanities and Social Science Invention, 3(1), 06-13.

Nygaard, C., \& Belluigi, D. Z. (2011). A proposed methodology for contextualised evaluation in higher education. Assessment and Evaluation in Higher Education, 36(6), 657-671. https://doi.org/10.1080/02602931003 650037.

Peleyeju, J. O. \& Ojebiyi, O. A. (2013). Lecturers' performance appraisal and total quality management of public universities in South-Western Nigeria. British Journal of Education, 1(2), 41-47.

Pramudyo, A. (2010). Analisis faktor-faktor yang mempengaruhi kinerja dosen negeri pada kopertis Wilayah $\mathrm{V}$ Yogyakarta. Jurnal Bisnis Teori \& Implementasi, 1(1), 1-11.

Ramli, R., \& Jalinus, N. (2013). Evaluasi kinerja guru sekolah menengah kejuruan Sumatera Barat pascasertifikasi. Jurnal Penelitian Dan Evaluasi Pendidikan, 17(1), 72-87. https://doi.org/10.21831/PEP.V17I1. 1362.

Ruslan. (2010). Kepuasan mahasiswa terhadap kinerja dosen. Jurnal Ilmu Pendidikan, 17, 230-237. https://doi.org/http://dx. doi.org/10.17977/jip.v17i3.2723

Shafa. (2014). Karakteristik proses pembelajaran Kurikulum 2013. Dinamika Ilmu, 14(32), 99-102. https://doi.org/10.1061/(ASCE) 0733 -9410(1991)117.

Sharko, A. D., Sharko, G, Demi, B, Baholli, I. (2015). Development of EUETLPE web application (UET online lecturer performance evaluation system). Journal of educational and social research, 5(2).

Sukirno \& Siengthai, S. (2011). Does participative decision making affect lecturer performance in higher education? International Journal of Educational Management,25(5), 494 508.

Universitas Negeri Yogyakarta. (2016). Rencana induk penelitian tabun 20162020. Yogyakarta: UNY.

Yen, W. M. (1993). Scaling performance assessment: Strategies for managing local item dependents. Journal of Educational Measurement, 3(3) 187-213. 